\title{
Assessment of proximal tubular sodium reabsorption during water diuresis in patients with heart disease
}

\author{
D. G. Gibson, J. C. Marshall, and Eunice Lockey \\ From National Heart Hospital, Westmoreland Street, London W.I
}

In order to examine the relation between cardiac state and the capacity to excrete a water load, Io normal subjects and 6I patients with heart disease were studied during water diuresis. Under these conditions, urine flow approximates to the rate of delivery of filtrate, and therefore of sodium, from the proximal tubule of the kidney to the loop of Henle, while free water clearance is a function of distal sodium reabsorption. In 12 patients with complete heart block, ventricular pacing was associated with increased urine flow and free water clearance. Oral propranolol in 3 normal subjects and in 9 patients with intact atrial septa caused a reduction, and oral practolol in 4 normal subjects and 8 patients caused no change. In 6 patients with atrial septal defect, propranolol was without effect. Maximum urine flow correlated with left ventricular end-diastolic pressure but not mean left atrial pressure in 16 patients with chronic rheumatic heart disease. In 7 patients with ischaemic heart disease, maximum urine flow was higher than in those with chronic rheumatic heart disease and similar increase in left ventricular end-diastolic pressure. These results reflect a close relation between proximal tubular sodium reabsorption and cardiac state, and suggest that inappropriate sodium reabsorption at this site may contribute to fluid retention in heart disease.

Reduction in the maximum rate of sodium excretion by the kidney is characteristic of severe heart disease, and the resulting fluid retention is of considerable importance in the pathogenesis of the clinical syndrome of heart failure. Sodium excretion by the mammalian kidney is a complex process involving the combined activity of several sites with different functional characteristics (Pitts, 1963). Though, in the normal kidney, the greater part of the sodium in the glomerular filtrate is reabsorbed in the proximal tubule, there is little information on the extent to which inappropriate activity at this site contributes to the retention of sodium occurring in patients with heart disease. Proximal tubular function in intact man may be assessed during water diuresis, since under these conditions urine flow approximates to the rate of delivery of fluid from the proximal tubule to the loop of Henle, the site of sodium reabsorption to form free water. The reduced capacity of patients with heart disease to excrete a water load (Leaf and Mamby, 1952) therefore reflects a diminution in the maximum rate of delivery of sodium from the proximal tubule to the distal part of the nephron (Bell, Schedl, and Bartter, 1964). In order to assess the imReceived 28 November 1969 . portance of abnormalities of proximal tubular function in patients with heart disease, we have studied the urine flow, free water clearance, and cation excretion during water diuresis, with particular reference to the relation with intracardiac pressures, and the effects of procedures known to cause a change in cardiac state.

\section{Methods}

Patients were studied in the open ward on a normal diet. After an overnight fast, they took an oral water load of $20 \mathrm{ml}$./kg. body weight between 8.30 and 9.30 a.m. All urine passed was collected at hourly intervals between 8.30 a.m. and r.30 p.m., and blood samples were taken at 8.30 a.m., Ir.30 a.m., and I.30 p.m. The patients remained in bed throughout the test and did not smoke. Diuretics were stopped 48 hours previously, but digitalis preparations were continued.

If urine specimens could not be analysed immediately, they were deep-frozen. Osmolality was determined with an 'Advance' osometer, urea by a microurease method, and sodium and potassium by flame photometry.

Osmolar clearance $\left(\mathrm{C}_{\mathrm{osm}}\right)$ was calculated as $\mathrm{U}_{\text {osm }} \mathrm{V} / \mathrm{P}_{\text {osm }}$ and free water clearance $\left(\mathrm{C}_{\mathrm{H}_{2} \mathrm{O}}\right)$ as $\mathrm{V}-\mathrm{C}_{\mathrm{osm}}$, where $\mathrm{U}_{\mathrm{osm}}=$ urine osmolality (mOsm/ kg.), $\mathbf{P}_{\text {osm }}=$ plasma osmolality ( $\mathrm{mOsm} / \mathrm{kg}$.), and $\mathrm{V}=$ urine flow $(\mathrm{ml} . / \mathrm{min}$.$) .$ 
The rate of sodium and potassium excretion was expressed in $\mu \mathrm{Eq}$ per minute. All values were taken from the hourly specimen with the largest volume, usually the second or third.

\section{Subjects}

(I) Normals Ten normal subjects were studied; 4 volunteers and 6 patients with systolic murmurs or wide splitting of the second heart sound in whom cardiac catheterization had failed to show any abnormality.

(2) Ventricular pacing Twelve patients with spontaneous ventricular rates of less than 40 per minute due to complete atrioventricular block were studied before, and two to seven days after the institution of ventricular pacing at approximately 70 beats a minute. The clinical indication for artificial pacing was either fluid retention, inadequately controlled by diuretic therapy, or repeated Adams-Stokes attacks.

(3) Propranolol Group A: This consisted of 3 normal subjects and 9 patients who received the drug orally, either for angina or to control dysrhythmias. None of the patients had clinical or radiological evidence of heart failure. Group $B$ : This consisted of 6 patients with ostium secundum atrial septal defects confirmed by cardiac catheterization, in whom the pulmonary to systemic flow ratio was greater than $2.5: \mathrm{r}$.

Both groups were studied before propranolol therapy, and after 5 days on the drug. The daily dose of propranolol for each patient is given in Table 2: one quarter of it was given orally on the morning of the second test.

(4) Practolol (ICI 50I72) Four normal volunteers and 8 patients with ischaemic heart disease or intractible dysrhythmias received the drug orally. They were studied in the same way as those taking propranolol.

(5) Cardiac catheterization Group A: This consisted of 16 patients with chronic rheumatic heart disease affecting mitral and aortic valves, who were under consideration for corrective cardiac operation. Group B: This consisted of 7 patients with intractible angina in whom left heart catheterization and coronary angiography were performed during assessment for a revascularization procedure. In both groups, pressures were measured before angiography and were referred to the mid-thorax.

\section{Results}

(I) Normals (Table $I$ ) The maximum rate of urine flow was between 8.2 and 16.0 $\mathrm{ml} / \mathrm{min}$. (mean II.5 ml./min.) with free water clearance between 6.2 and $\mathrm{II} \cdot 4 \mathrm{ml}$./ min. (mean $8.5 \mathrm{ml} . / \mathrm{min}$.). The mean rates of sodium and potassium excretion were 99 and $53 \mu \mathrm{Eq} / \mathrm{min}$., respectively.

(2) Ventricular pacing (Table 3) Before the institution of ventricular pacing the maxi-
TABLE I Normal subjects

\begin{tabular}{l|rr|rc}
\hline $\begin{array}{l}\text { Case } \\
\text { No. }\end{array}$ & $V$ & $\begin{array}{c}C_{\mathrm{H}_{2} \mathrm{O}} \\
(\text { ml./min. })\end{array}$ & $N a$ & $\begin{array}{c}K \\
(\mu E q / \text { min. })\end{array}$ \\
\hline $\mathrm{I}$ & 11.5 & $9 \cdot 2$ & 60 & 40 \\
2 & 9.6 & 7.8 & 48 & 20 \\
3 & 14.2 & $9 \cdot 6$ & 150 & 70 \\
4 & 10.3 & 7.0 & 110 & 62 \\
5 & 12.7 & 9.6 & 200 & 80 \\
6 & 16.0 & 11.4 & 130 & 60 \\
7 & $11 \cdot 2$ & 8.5 & 40 & 40 \\
8 & 8.2 & 6.2 & 20 & 70 \\
9 & 10.0 & 6.7 & 120 & 60 \\
10 & 11.1 & 9.0 & 110 & 30 \\
\hline
\end{tabular}

mum urine flow and free water clearance were considerably below those of the normal group $(p<0.001)$. Ventricular pacing at a rate of $70 / \mathrm{min}$. was associated with a mean increase in urine flow of $1.8 \mathrm{ml} . / \mathrm{min}$. ( $\mathrm{p}<$ $0.00 \mathrm{I}$ ), and in free water clearance of $\mathrm{I} \cdot 3 \mathrm{ml} . /$ min. $(p<0.01)$. In addition, there was a significant rise in the rate of sodium excretion of $46 \mu \mathrm{Eq} / \mathrm{min}$. $(\mathrm{p}<0.05)$. Though potassium excretion was reduced in all but three patients, the change did not reach statistical significance.

(3) Propranolol (Table 2) Group A: Propranolol administration was associated with a highly significant reduction in urine flow of $2.3 \mathrm{ml} . / \mathrm{min}$. $(p<0.00 \mathrm{r})$ and in free water clearance of $1.5 \mathrm{ml} . / \mathrm{min}$. ( $p<0.01)$. There was no significant change in the rate of sodium or potassium excretion. Group $B$ :

TABLE 2 Results in cases given propranolol

\begin{tabular}{|c|c|c|c|c|c|c|c|c|c|}
\hline \multirow[b]{2}{*}{$\begin{array}{l}\text { Case } \\
\text { No. }\end{array}$} & \multirow[b]{2}{*}{$\begin{array}{l}\text { Dose } \\
\text { (mg./24 hr.) }\end{array}$} & \multicolumn{4}{|c|}{ Control } & \multicolumn{4}{|c|}{ Propranolol } \\
\hline & & $V_{(m l}$ & $\begin{array}{l}C_{\mathrm{H}_{2} \mathrm{O}} \\
\text { min.) }\end{array}$ & $\begin{array}{l}N a \\
\quad(\mu E\end{array}$ & $\begin{array}{l}K \\
(\min .)\end{array}$ & $V$ & $\begin{array}{l}C_{\mathrm{H}_{2} \mathrm{O}} \\
(\min .)\end{array}$ & $\begin{array}{l}N a \\
(\mu E q\end{array}$ & $\underset{m i n .)}{K}$ \\
\hline \multicolumn{10}{|c|}{ Group $A$} \\
\hline I & 80 & $5 \cdot 2$ & 3.0 & 15 & 35 & 3.5 & $I \cdot 7$ & 50 & I5 \\
\hline 2 & 40 & $6 \cdot 1$ & $I \cdot I$ & 40 & IIO & $2 \cdot 0$ & $-0 . \mathbf{I}$ & 10 & 90 \\
\hline 3 & 80 & 16.0 & II 4 & 40 & 15 & II $\cdot 7$ & 9.0 & 90 & 60 \\
\hline 4 & 30 & $7 \cdot 3$ & $4 \cdot 3$ & 140 & 70 & $6 \cdot 3$ & $4 \cdot 2$ & 100 & 30 \\
\hline 5 & 120 & $8 \cdot 2$ & $5 \cdot 8$ & 80 & 60 & $5 \cdot 5$ & $3 \cdot 8$ & 50 & 55 \\
\hline 6 & 30 & I I 7 & IO. I & 70 & 20 & 10.1 & $7 \cdot 8$ & 90 & 50 \\
\hline 7 & 80 & 6.8 & $4 \cdot 4$ & 40 & 35 & 2.5 & 0.5 & 40 & 30 \\
\hline 8 & 40 & $4 \cdot 4$ & $2 \cdot 4$ & 50 & 30 & $4 \cdot 3$ & $2 \cdot 6$ & 90 & 70 \\
\hline 9 & 80 & $6 \cdot 1$ & $4 \cdot 5$ & 30 & 60 & $5 \cdot 2$ & 3.5 & 75 & 40 \\
\hline 10 & 40 & $8 \cdot 2$ & $6 \cdot 2$ & 20 & 70 & 8.7 & $6 \cdot 2$ & 40 & 70 \\
\hline I I & 40 & I2.7 & $9 \cdot 6$ & 200 & 80 & II'S & 8.9 & 90 & 50 \\
\hline 12 & 40 & $14 \cdot 2$ & 9.6 & I 50 & 70 & $8 \cdot 3$ & $6 \cdot 0$ & 50 & 50 \\
\hline \multicolumn{10}{|c|}{ Group B: Atrial septal defect } \\
\hline $\mathbf{I}$ & 80 & $5 \cdot 5$ & $4 \cdot 3$ & 45 & 5 & $5 \cdot 4$ & $4 \cdot 2$ & 60 & Io \\
\hline 2 & 40 & $5 \cdot 5$ & $3 \cdot 8$ & 60 & 30 & $3 \cdot 4$ & $2 \cdot 4$ & 15 & 20 \\
\hline 3 & 40 & $6 \cdot 1$ & $3 \cdot 6$ & I90 & 45 & $8 \cdot 2$ & $6 \cdot 1$ & 120 & 90 \\
\hline 4 & 40 & $8 \cdot 3$ & $5 \cdot 9$ & 190 & 50 & II O O & 9.5 & 90 & 20 \\
\hline 5 & 40 & 8.0 & 6.0 & 65 & 25 & $9 \cdot 3$ & $6 \cdot 3$ & 140 & 60 \\
\hline 6 & 40 & $1 \cdot 0$ & 0.07 & 3 & 13 & $4 \cdot 2$ & 2.9 & 21 & 30 \\
\hline
\end{tabular}


In the patients with ostium secundum atrial septal defect, propranolol caused a mean increase of $\mathrm{I} \cdot 2 \mathrm{ml} . / \mathrm{min}$. in urine flow. This was not significantly different from the control value, but the response was significantly different from that found in patients with intact atrial septa. (Difference of means $3.5 \mathrm{ml}$./min., standard error of difference $0.94, \mathrm{p}<0.01$.)

(4) Practolol (Table 4) Practolol administration was not associated with significant change in urine flow, free water clearance, or sodium or potassium excretion rate.

(5a) Intracardiac pressures in chronic rheumatic heart disease The results in the patients with chronic rheumatic heart disease are shown in Fig. I. In II patients, the mean left atrial pressure was significantly higher than the left ventricular end-diastolic pressure, due to the presence of mitral valve disease, allowing the effects of increases of pressure at the two sites to be assessed independently. There was a highly significant correlation between left ventricular end-diastolic pressure and $\mathrm{V}(\mathrm{r}=-0.76, \mathrm{p}<0.00 \mathrm{I})$, a raised end-diastolic pressure always being associated with reduced urine flow. Mean left atrial pressure in these 16 patients was not related to $V$, and in the presence of a normal left ventricular end-diastolic pressure, conspicuous increases of left atrial pressure did not prevent normal or near normal maximum rates of urine flow.

(5b) Ischaemic heart disease In 7 patients with ischaemic heart disease the maximum rate of urine flow was considerably greater than that occurring in patients with chronic rheumatic heart disease and comparable left ventricular end-diastolic pressures.

The results are shown in Fig. 2, together with the regression line and limits placed at 2 standard errors of the estimate of urine flow derived from Group A. The difference between the 2 groups is therefore highly significant.

(6) Maximum urine flow and maximum free water clearance The relation between maximum urine flow and maximum free water clearance is shown in Fig. 3. It is apparent that at lower levels of $\mathrm{V}$, there is a progressive reduction in free water excreted per unit urine flow, with formation of urine hypertonic to plasma in 4 cases. This was associated with an increase in the concentration of urine urea from $150-300 \mathrm{mg} . / 100 \mathrm{ml}$.
TABLE 3 Ventricular pacing

\begin{tabular}{|c|c|c|c|c|c|c|c|c|}
\hline \multirow[b]{2}{*}{$\begin{array}{l}\text { Case } \\
\text { No. }\end{array}$} & \multicolumn{4}{|c|}{ Control } & \multicolumn{4}{|c|}{ Paced } \\
\hline & $V$ & ${ }^{(\min .)}{ }_{\mathrm{H}_{2} \mathrm{O}}$ & $N a$ & $\begin{array}{c}K \\
(\mu E q / \min .)\end{array}$ & $V$ & $\begin{array}{l}C_{\mathrm{H}_{2} \mathrm{O}} \\
(\min .)\end{array}$ & $\mathrm{Na}$ & $\underset{(\min .)}{K}$ \\
\hline I & 5.5 & 3.5 & 20 & 50 & $6 \cdot 8$ & 4.5 & 55 & 45 \\
\hline 2 & $4 \cdot 6$ & $1 \cdot 5$ & 20 & 80 & $6 \cdot 3$ & $4 \cdot 0$ & 25 & 45 \\
\hline 3 & $\mathrm{I} \cdot 6$ & 0.2 & IO & 40 & $6 \cdot 7$ & $4 \cdot 7$ & 40 & 25 \\
\hline 4 & $6 \cdot 5$ & $4 \cdot 3$ & 60 & 30 & $8 \cdot 2$ & $3 \cdot 4$ & 330 & ICO \\
\hline 5 & 5.8 & $1 \cdot 9$ & 70 & 95 & $7 \cdot 8$ & 2.5 & 90 & 90 \\
\hline 6 & 3.0 & 0.5 & 90 & 35 & $3 \cdot 2$ & $\mathrm{I} \cdot 6$ & 90 & 20 \\
\hline 7 & 3.5 & 2.0 & 20 & 40 & $7 \cdot 0$ & $5 \cdot 2$ & 70 & 30 \\
\hline 8 & 3.7 & 0.0 & 30 & 90 & 4.0 & 0.5 & 30 & 70 \\
\hline 9 & $3 \cdot 8$ & $1 \cdot 5$ & 50 & 35 & $4 \cdot 5$ & $3 \cdot 3$ & 27 & 13 \\
\hline 10 & $4 \cdot 4$ & $2 \cdot 6$ & 45 & 35 & $6 \cdot 3$ & $I \cdot 8$ & 130 & 30 \\
\hline I I & 5.9 & $4 \cdot 4$ & 30 & 25 & 8.0 & $6 \cdot 1$ & 105 & 30 \\
\hline 12 & $I \cdot 7$ & -0.2 & 60 & 40 & 3.0 & 0.8 & 60 & 50 \\
\hline
\end{tabular}

TABLE 4 Results in cases given practolol (ICI 50I72)

\begin{tabular}{|c|c|c|c|c|c|c|c|c|c|}
\hline \multirow[b]{2}{*}{$\begin{array}{l}\text { Case } \\
\text { No. }\end{array}$} & \multirow[b]{2}{*}{$\begin{array}{l}\text { Dose } \\
\text { (mg./24 hr.) }\end{array}$} & \multicolumn{4}{|c|}{ Control } & \multicolumn{4}{|c|}{ Practolol } \\
\hline & & $V_{(n}$ & $\begin{array}{c}C_{\mathrm{H}_{2} \mathrm{O}} \\
(\operatorname{min.})\end{array}$ & $\begin{array}{c}N a \\
(\mu)\end{array}$ & $\underset{\text { (min.) }}{K}$ & $V_{(m}$ & $\underset{(\min .)}{C_{\mathrm{H}_{2} \mathrm{O}}}$ & $\underset{(\mu)}{N a}$ & $\underset{q / \min .)}{K}$ \\
\hline I & 100 & II.5 & $7 \cdot 8$ & 200 & 70 & $16 \cdot 0$ & I I $\cdot 2$ & 390 & 80 \\
\hline 2 & 150 & $5 \cdot 8$ & $4 \cdot I$ & $4 \mathrm{I}$ & 75 & $5 \cdot 4$ & 3.8 & 28 & 87 \\
\hline 3 & 100 & 10.2 & $6 \cdot 4$ & 92 & II3 & $9 \cdot 8$ & $6 \cdot 8$ & 105 & 97 \\
\hline 4 & 200 & $8 \cdot 3$ & $6 \cdot 6$ & 17 & 25 & 10.5 & $8 \cdot 2$ & 31 & 40 \\
\hline 5 & 400 & $7 \cdot 4$ & $6 \cdot 0$ & 15 & 75 & $7 \cdot 0$ & $5 \cdot 0$ & 140 & 410 \\
\hline 6 & 150 & 3.8 & $2 \cdot 7$ & I5 & 23 & $3 \cdot 0$ & $I \cdot 6$ & 15 & 15 \\
\hline 7 & 100 & IIIO & 8.5 & 44 & 44 & 10.5 & $7 \cdot 9$ & 72 & 72 \\
\hline 8 & 100 & $8 \cdot 2$ & $6 \cdot 2$ & 16 & 73 & $8 \cdot 0$ & 5.6 & 32 & 88 \\
\hline 9 & 100 & $12 \cdot 7$ & $9 \cdot 6$ & 205 & 76 & 14.0 & II $\cdot 0$ & 240 & 84 \\
\hline 10 & 100 & 14.0 & $9 \cdot 6$ & 150 & 72 & 10.5 & $7 \cdot 7$ & 95 & 80 \\
\hline II & 200 & 0.6 & 0.07 & I & 4 & $3 \cdot 2$ & $2 \cdot 4$ & 13 & 23 \\
\hline 12 & 150 & $7 \cdot 8$ & 5.4 & 23 & 140 & $10 \cdot 7$ & $8 \cdot 4$ & 25 & 100 \\
\hline
\end{tabular}

in normal subjects to $2600 \mathrm{mg} . / 100 \mathrm{ml}$. in patients with very low urine volume (Fig. 4).

\section{Discussion}

The mechanism of sodium and of water excretion by the kidney has been reviewed by Pitts (1963). The wall of the proximal tubule is freely permeable to water, and so active reabsorption of sodium is accompanied by passive movement of water to maintain osmotic equilibrium. Under normal circumstances, approximately 75 per cent of the glomerular filtrate is reabsorbed in this way, but considerable variation may occur in this, and hence in the rate of delivery of sodium to the loop of Henle. The loop of Henle is impermeable to water, so that active reabsorption of sodium occurring in the ascending limb causes the fluid entering the distal tubule to be hypotonic to plasma. Since the distal tubule is also impermeable to water, this osmotic gradient is maintained until the fluid enters the collecting duct. As a result of the 


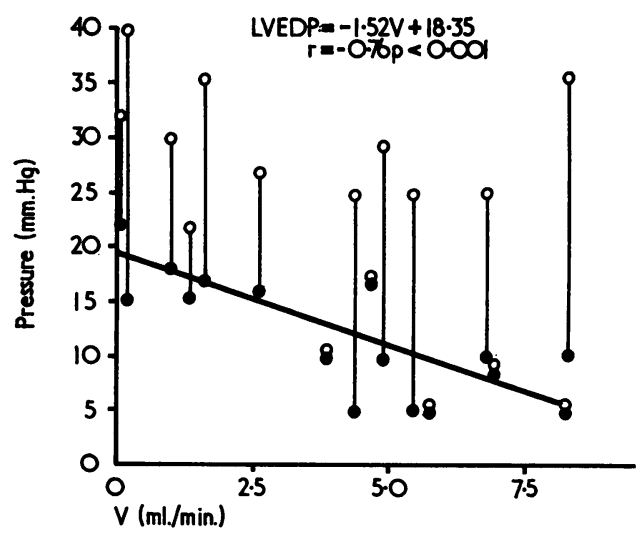

FIG. I Relation between mean left atrial pressure (O), left ventricular end-diastolic pressure $(\mathrm{O})$, and maximum rate of urine secretion $(V)$ in 16 patients with chronic rheumatic heart disease. Points corresponding to left ventricular end-diastolic pressure and mean left atrial pressure for the same patient are joined by a line, the difference being due to the presence of mitral valve disease. There is a significant relation between $V$ and left ventricular end-diastolic pressure shown by the regression line, but not between $V$ and the mean left atrial pressure.

arrangement of the loops of Henle, sodium abstracted from the lumen is concentrated in the renal medulla by a countercurrent mechanism, the interstitial fluid becoming hypertonic to plasma. In the presence of antidiuretic hormone (ADH), osmotic equilibrium between the fluid in the collecting duct and in

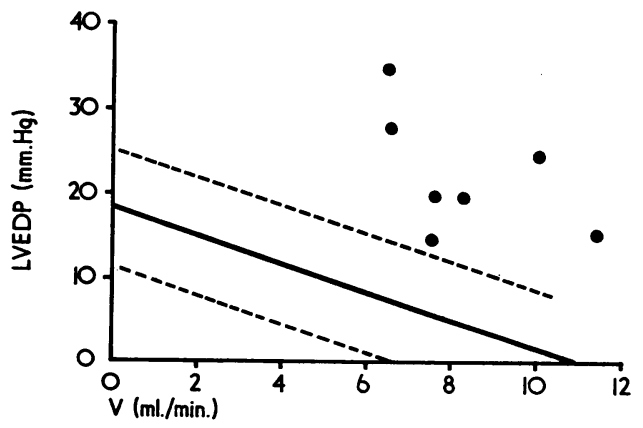

FIG. 2 Relation between left ventricular end-diastolic pressure and maximum rate of urine secretion $(V)$ in 7 patients with ischaemic heart disease. The regression line with limits placed at 2 standard errors of the left ventricular end-diastolic pressure is derived from the patients with chronic rheumatic heart disease.

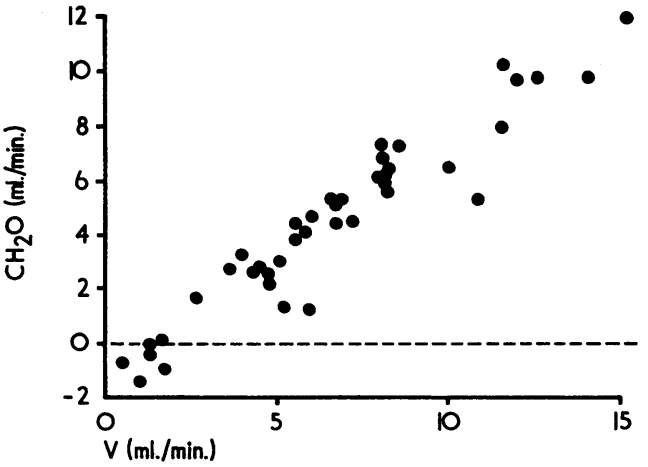

FIG. 3 Relation between maximum urine flow $(V)$ and maximum rate of free water clearance $\left(C_{\mathrm{H}_{2} \mathrm{O}}\right)$ for the whole group of patients. Negative free water clearances indicate the production of urine hypertonic to plasma, occurring at low rates of urine flow.

the renal medulla occurs, but in its absence, as during water diuresis or in patients with diabetes insipidus, the collecting duct remains impermeable to water and so the urine is hypotonic to plasma. Under these conditions, urine flow is equal to the volume of filtrate leaving the proximal tubule in unit time and therefore closely related to the rate of delivery of sodium to the loop of Henle (Eknoyan et al., 1967).

In patients with low heart rate due to complete heart block, ventricular pacing causes an increase in cardiac output (Sowton, 1964) and improvement in the clinical signs of heart failure. Improvement in renal function after the institution of ventricular pacing has also been observed by Humphries et al. (1967) though our results differ from theirs

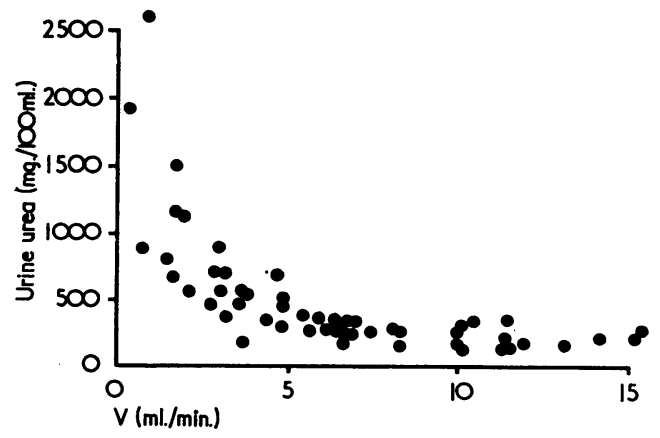

FIG. 4 Effect of urine flow (V) on urine urea concentration for the whole group of patients, showing a considerable increase in urine urea concentration at low rates of urine flow. 
in showing such improvement consistently within a few days of the onset of pacing. An increase in the rate of sodium excretion has also been documented by Dekker (1969) though his patients were not studied during water diuresis. Propranolol reduces cardiac output at rest and on exercise (Epstein et al., 1965) and may precipitate or aggravate clinical signs of heart failure (Stephen, 1966).

Practolol differs from propranolol in showing marked selectivity for cardiac beta adrenergic sites (Dunlop and Shanks, 1968), in having intrinsic sympathomimetic activity (Dunlop and Shanks, 1968), and, in addition, in causing less reduction of cardiac output in relation to that of heart rate both in patients with ischaemic heart disease (Sowton et al., 1968) and in normal subjects during exercise (Gibson and Sowton, 1968). In these situations, therefore, changes in the maximum rate of urine flow and in free water clearance correlate with changes in cardiac state, and with the tendency to develop clinical manifestations of heart failure.

Oral propranolol did not change the maximum rate of urine flow in patients with ostium secundum atrial septal defect. There is no evidence to suggest that the left ventricle of such patients responds abnormally to propranolol, and it seems likely that the lack of effect on renal function was due to the presence of an intracardiac shunt. In the normal circulation, venous return to the right atrium is closely related to aortic flow, and when left ventricular function is depressed, cardiac output may be maintained by an increase in the left ventricular end-diastolic and therefore of the left atrial pressure. In contrast, in the presence of an atrial septal defect, pulmonary blood flow, and therefore blood flow to the right atrium, may be several times that through the systemic circulation, and, in addition, an increase in left atrial pressure can no longer accompany depressed left ventricular function, since any increase causes increased blood flow across the defect. If the changes in renal function occurring during propranolol administration in patients with intact atrial septa were due to some alteration in aortic pressure or flow consequent upon depressed left ventricular function, then it might be anticipated that they would occur in a similar manner, or even be accentuated in patients with atrial septal defect, due to failure of the left ventricular end-diastolic pressure to rise. Their absence in such patients suggests that they are related, rather, to factors controlling venous return to the right atrium, which may be unchanged or even increased by propranolol administration due to the presence of the defect. Further, the lack of effect of propranolol in patients with atrial septal defect makes it unlikely that the drug has a direct effect on renal function.

In the group of patients with chronic rheumatic heart disease, maximum urine flow was inversely correlated with left ventricular end-diastolic pressure. All these patients are likely to have had left ventricular disease, and an increase in left ventricular end-diastolic pressure probably reflected the resulting impairment in cardiac function, rather than influencing sodium reabsorption directly. In patients with mitral valve disease, mean left atrial pressure was higher than the end-diastolic pressure, but a specific effect of raised pressure at this site seems unlikely in view of the lack of correlation with maximum urine flow. The results in the group of patients with ischaemic heart disease, where urine flow was greater at a given end-diastolic pressure than in the patients with rheumatic heart disease, may reflect differences in the mechanical properties of the left ventricle in the 2 conditions, and provide further confirmation that left ventricular end-diastolic pressure is not a primary determinant of renal function. The increased maximum urine flow in these patients compared with those with rheumatic heart disease correlated with the clinical observation that none of them had developed significant fluid retention, a finding similar to that of Gorlin, Klein, and Sullivan (1967) in patients with ventricular aneurysm.

In heart disease, limitation of free water excretion in response to a water load is mainly attributable to increased proximal tubular reabsorption of sodium (Bell et al., 1964). However, antidiuretic activity has been reported in serum and urine, raising the possibility that inappropriate secretion of $\mathrm{ADH}$ might contribute to this abnormality, particularly in those patients who show complete inability to excrete free water (Bartter and Schwartz, 1967). In occasional patients with congestive heart failure (Lamdin et al., 1956), ethyl alcohol, an inhibitor of $\mathrm{ADH}$ release, may cause a considerable diuresis, particularly in those who develop transient oliguria, hyponatraemia, and fluid retention after mitral valvotomy (D'Angelo, Murdaugh, and Sealy, 1958). However, such a response is unusual, and reduced urine flow in the present series of patients was likely to have been due to increased proximal tubular reabsorption of sodium. There was a close relation between urine volume and free water clearance (Fig. 3), but at lower levels of urine volume there was a reduction in the rate of excretion of free water per unit of urine 
flow. This was due, in part, to an increase in the urine urea concentration, compatible with the reabsorption of an increasing proportion of proximal tubular fluid (Fig. 4). Similar reduction in the free water clearance per unit of urine flow occurs at high flow rates during mannitol diuresis, and has been attributed to an increasing concentration of a non-reabsorbable solute (mannitol) in the tubular fluid at the diluting site (Eknoyan et al., 1967). A second factor is likely to be back diffusion between the tubule and interstitial fluid, which is negligible at high flow rates, but which becomes progressively more important as urine flow drops. Its significance has been documented in man by the production of urine hypertonic to plasma in patients with diabetes insipidus by acute reduction of the glomerular filtration rate (Kleeman, Maxwell, and Rockney, 1957). Four patients produced urine hypertonic to plasma throughout the test. However, it appears (Fig. 3) that a similar relation between urine volume and free water clearance applies throughout the whole group of patients studied, and that at flow rates below $\mathrm{I}-\mathrm{I} \cdot 5 \mathrm{ml} / \mathrm{min}$. complete failure to excrete free water would be anticipated. It does not, therefore, seem necessary to consider such patients as a separate group or to invoke another explanation to explain the observed response.

The present results therefore suggest that the rate of delivery of sodium from the proximal tubule to the loop of Henle is closely related to the cardiac state of the patient. Such a reduction in sodium delivery might be due to reduced glomerular filtration or, more likely, to increased proximal tubular sodium reabsorption, since changes in glomerular filtration rate occurring in heart disease are not large enough to account for the present observations (Hollander and Judson, 1956). Proximal tubular sodium reabsorption has been extensively studied in the experimental animal. It is reduced by expansion of plasma volume (de Wardener et al., 196I), by reduction in plasma oncotic pressure, or by renal vasodilatation (Daugharty et al., 1968), and is responsible for increased urine flow in DOCA-escaped animals (Wright et al., 1969). In man, increased proximal tubular sodium reabsorption, caused by depletion of total body sodium, has been suggested as an explanation of the reduced urine flow in patients with diabetes insipidus during treatment with thiazide diuretics. While the mechanism of its regulation is not clear, it does not appear that aldosterone plays a significant role (Daugharty et al., 1968).

Braunwald, Plauth, and Morrow (1965) have studied the effects of heart disease on the maximum rate of sodium excretion during oral sodium loading and found a significant relation with the functional classification of the patient, but not with intracardiac pressures. Propranolol, though causing reversal of the normal diurnal rhythm of sodium excretion, did not have any consistent effect on the maximum rate (Epstein, 1966). Spironolactone, however, caused a considerable increase in 3 patients (Braunwald et al., 1965), suggesting that distal tubular sodium reabsorption, mediated by aldosterone, was a primary factor determining the maximum rate of sodium excretion in such patients, and that apparent inconsistencies between the two tests may reflect differences in the pattern of sodium excretion. Mild mitral stenosis, in the absence of haemodynamic abnormality at rest, caused a reduction in the maximum rate of sodium excretion (Braunwald et al., 1965), whereas, in the present study, mitral valve disease severe enough to cause a mean wedge pressure of $30 \mathrm{~mm}$. $\mathrm{Hg}$, in the presence of a normal left ventricular end-diastolic pressure, was associated with normal or only slightly reduced urine flow and free water clearance. During propranolol administration, the reverse pattern is seen, with a consistent reduction in urine flow after a water load but with no change in the maximum rate of sodium excretion. Increase in heart rate by ventricular pacing in patients with complete heart block appears to be associated with an increase in the maximum rates of both sodium excretion and urine flow. It is therefore suggested that inappropriate sodium reabsorption may occur by proximal or distal tubular mechanisms in patients with heart disease and that both may cause clinically important fluid retention. While distal tubular sodium reabsorption is influenced by aldosterone, proximal tubular function is related to cardiac state and in particular to some aspect of the maintenance of venous return rather than to aortic pressure or flow. An oral water load test may therefore be useful in localizing such abnormalities, as well as being a sensitive method of documenting changes in cardiac state due to drugs or other manoeuvres. It is very simple to carry out, and we have seen no significant complications in 150 such tests, many of which were performed on patients with severe heart disease.

We are grateful to Dr. D. Benett and Dr. Eldon Smith for their contributions, to Mr. A. F. Kamalagharan for technical assistance, to the physicians and surgeons at the National Heart 
Hospital for permission to study their patients, and to Dr. D. Fitzgerald for supplies of practolol (ICI 50172).

\section{References}

Bartter, F. C., and Schwartz, W. B. (1967). The syndrome of inappropriate secretion of antidiuretic hormone. American fournal of Medicine, 42, 790.

Bell, N. H., Schedl, H. P., and Bartter, F. C. (1964). An explanation for abnormal water retention and hypoosmolality in congestive heart failure. American fournal of Medicine, 36, 35I.

Braunwald, E., Plauth, W. H., Jr., and Morrow, A. G. (1965). A method for the detection and quantification of impaired sodium excretion. Results of an oral sodium tolerance test in normal subjects and in patients with heart disease. Circulation, 32, 223.

D'Angelo, G. J., Murdaugh, H. V., Jr., and Sealy, W. C. (1958). The nature and treatment of the postcommissurotomy hyponatremic syndrome. Surgery, Gynecology and Obstetrics, 106, 87.

Daugharty, T. M., Belleau, L. J., Martino, J. A., and Earley, L. E. (1968). Interrelationship of physical factors affecting sodium reabsorption in the dog. American fournal of Physiology, 215, 1442.

Dekker, E. (1969). Influence of electronically paced ventricular rate on urine flow and excretion of minerals in patients with total heart block. British Heart fournal, 31, 184.

de Wardener, H. E., Mills, I. H., Clapham, W. F., and Hayter, C. J., (I96I). Studies on the efferent mechanism of the sodium diuresis which follows the administration of intravenous saline in the dog. Clinical Science, 21, 249.

Dunlop, D., and Shanks, R. G. (1968). Selective blockade of adrenoceptive beta receptors in the heart. British fournal of Pharmacology and Chemotherapy, 32, 201.

Eknoyan, G., Suki, W. N., Rector, F. C., Jr., and Seldin, D. W. (1967). Functional characteristics of the diluting segment of the dog nephron and the effect of extracellular volume expansion on its reabsorptive capacity. fournal of Clinical Investigation, 46, II 18 .

Epstein, S. E. (1966). Discussion - on side effects (of propranolol) - to Stephen (1966). American fournal of Cardiology, 18, 468.

- Robinson, B. F., Kahler, R. L., and Braunwald,
E. (1965). Effects of beta-adrenergic blockade on the cardiac response to maximal and submaximal exercise in man. fournal of Clinical Investigation, $44,1745$.

Gibson, D., and Sowton, E. (1968). Effects of I.C.I. 50172 in man during erect exercise. British Medical fournal, I, 213.

Gorlin, R., Klein, M. D., and Sullivan, J. M. (1967). Prospective correlative study of ventricular aneurysm. Mechanistic concept and clinical recognition. American fournal of Medicine, 42, 512.

Hollander, W., and Judson, W. E. (I956). The relationship of cardiovascular and renal hemodynamic function to sodium excretion in patients with severe heart disease but without edema. fournal of Clinical Investigation, 35, 970.

Humphries, J. O., Hinman, E. J., Bernstein, L., and Walker, W. G. (1967). The effect of artificial pacing of the heart on cardiac and renal function. Circulation, 36, 717.

Kleeman, C. R., Maxwell, M. H., and Rockney, R. (1957). Production of hypertonic urine in humans in the probable absence of antidiuretic hormone. Proceedings of the Society for Experimental Biology and Medicine, 96, 189.

Lamdin, E., Kleeman, C. R., Rubini, M., and Epstein, F. H. (1956). Studies on alcohol diuresis III. The response to ethyl alcohol in certain disease states characterized by impaired water tolerance. fournal of Clinical Investigation, 35, 386.

Leaf, A., and Mamby, A. R. (1952). An antidiuretic mechanism not regulated by extracellular fluid tonicity. Fournal of Clinical Investigation, 31, 60.

Pitts, R. F. (1963). Physiology of the Kidney and Body Fluids, p. 188. Year Book Medical Publishers, Chicago.

Sowton, E. (1964). Haemodynamic studies in patients with artificial pacemakers. British Heart fournal, 26, 737 .

—, Balcon, R., Cross, D., and Frick, H. (1968). Haemodynamic effects of I.C.I. 50172 in patients with ischaemic heart disease. British Medical fournal, $1,215$.

Stephen, S. A. (1966). Unwanted effects of propranolol. American fournal of Cardiology, 18, 463.

Wright, F. S., Knox, F. G., Howards, S. S., and Berliner, R. W. (1969). Reduced sodium reabsorption by the proximal tubule of DOCA-escaped dogs. American fournal of Physiology, 216, 869. 